\title{
Effectively Utilising Teaching Assistants to Support Mathematics Learning: Some Insights from the Getting Ready in Numeracy (G.R.I.N.) Program
}

\author{
Penelope Kalogeropoulos ${ }^{1}$, James Russo ${ }^{{ }^{\star}}$, Toby Russo ${ }^{2}$, Peter Sullivan ${ }^{1}$ \\ ${ }^{7}$ Monash University, AUSTRALIA \\ ${ }^{2}$ Victorian Department of Education, AUSTRALIA \\ *CORRESPONDENCE: $\otimes$ james.russo@monash.edu
}

\begin{abstract}
Teaching assistants are not always utilised effectively in mathematics classrooms. Moreover, there is limited research examining instructional models that might more meaningfully incorporate teaching assistants into the teaching and learning of mathematics. To address this gap in the literature, the current study explored three distinct teacher-tutor dyads involved in a particular intervention program, Getting Ready in Numeracy (G.R.I.N.), from a single Australian primary school. All three tutors currently operated as teaching assistants in the classrooms of their G.R.I.N. teacher counterparts. The professional working relationships between G.R.I.N. teachers and their respective tutors were investigated through interviews. We outline common themes between the different dyads' approaches to G.R.I.N., and argue that all three dyads' practices are consistent with principles outlined in the literature around the effective utilisation of teaching assistants. We conclude by synthesising our findings, and presenting an embedded tutor model for the G.R.I.N. program. This model is presented as a prototype of good practice in a context where G.R.I.N. has been implemented successfully, whilst also serving as a more general model for how teaching assistants can be meaningfully incorporated into mathematics intervention programs.
\end{abstract}

Keywords: primary education, teaching assistants, intervention programs, inclusive education, professional partnerships

\section{INTRODUCTION}

There is a paucity of literature concerning how a teacher and teaching assistant might work together to support students who are underperforming in mathematics. This paper explores the value of a teacher working closely with a teaching assistant in an intervention context, specifically the Getting Ready in Numeracy (G.R.I.N.) program. The purpose of the current design-based study was two-fold. First, we intended to examine whether the manner in which teaching assistants are utilised within G.R.I.N. reflects 'good practice' principles of utilising teaching assistants in classrooms more generally, as articulated in a number of review studies (e.g., Giangreco, 2013; Sharma \& Salend, 2016). Second, we wished to develop a prototypical 'good practice' model of how tutor and teacher dyads may work within G.R.I.N. to support future schools implementing the G.R.I.N. program.

Article History: Received 16 March $2020 \bullet$ Revised 21 May 2020 • Accepted 22 May 2020

(C) 2020 by the authors; licensee Modestum Ltd., UK. Open Access terms of the Creative Commons Attribution 4.0 International License (http://creativecommons.org/licenses/by/4.0/) apply. The license permits unrestricted use, distribution, and reproduction in any medium, on the condition that users give exact credit to the original author(s) and the source, provide a link to the Creative Commons license, and indicate if they made any changes. 


\section{Overview of the G.R.I.N. Program}

The G.R.I.N. program is an initiative developed by Sullivan that aims to reengage disengaged students by preparing them for the subsequent mathematics lesson (Sullivan \& Gunningham, 2011). At its core, it involves G.R.I.N. students attending a tutoring session before their mathematics lesson multiple times per week. In this session, students are provided with an opportunity to work alongside a small group of peers and an appointed G.R.I.N. tutor to explore targeted practice, language development and to obtain familiarity with key pre-requisite concepts that will be the focus of the mathematics lesson that will follow (Sullivan \& Gunningham, 2011).

G.R.I.N. has been developed around three design principles, a cognitive-load rationale, a cognitive-affective rationale and a social-cognitive rationale. To summarise:

Principle 1 (Cognitive-load rationale): Students behind in mathematics will benefit from exploring the relevant concepts and procedures before the whole-class lesson, particularly if the content is sufficiently broken down for students.

Principle 2 (Cognitive-affective rationale): Students with low self-concept as mathematicians, who become familiar with concepts and procedures in advance of the whole-class lesson, are more likely to participate fully in the lesson, and develop a mastery-orientation towards mathematics.

Principle 3 (Social-cognitive rationale): Students benefit by learning mathematics through discussion and exploration of concepts and procedures with peers (Kalogeropoulos, Russo, Sullivan, Klooger, \& Gunningham, 2020, p. 3).

A school commits to engaging in the G.R.I.N. program for at least one year. This involves G.R.I.N. teachers and tutors attending three days of professional learning to support the implementation of G.R.I.N. back at their school, as well as at least one relevant instructional leader attending the first professional learning day.

Selecting students who are likely to benefit most from G.R.I.N. for participation in the program is important. In general, students who are under-achieving in mathematics in the middle years of primary school and beyond (generally Years 3 and above) are targeted. Schools are encouraged to try and select students who can realistically 'catch-up' to their peers through the duration of their participation (which is generally 6 to 12 months). Consequently, schools are encouraged to try and recruit students achieving in the second bottom quintile, whose lack of engagement in mathematics appears to arise from confusion with the content (Kalogeropoulos et al., 2020). For a more detailed discussion unpacking the mechanics of the G.R.I.N. program and the rationale underpinning it, see Kalogeropoulos et al., (2020).

Once a school has committed to implementing the G.R.I.N. program, many decisions need to be made that are critical to maximising the program's success at a given school. These decisions usually begin with the leadership team. When will G.R.I.N. be timetabled? When will the tutor and teacher meet to plan the G.R.I.N. sessions and to review and assess student progress and achievement? Who will be the tutor(s) and which mathematics teacher(s) should they be paired with? Although the G.R.I.N. tutor can be an individual with specific expertise in mathematical pedagogies (e.g., a Mathematics Learning Specialist, or Numeracy Leader), the program allows for any educational worker who has completed the requisite training to run the G.R.I.N. sessions. In most instances, the G.R.I.N. tutor is a teaching assistant.

\section{The Role of Teaching Assistants in Providing Instructional Support}

The personnel hired by schools to assist classroom teachers and special educators in their efforts to educate students with additional learning needs are known by a variety of names (depending on the country/ jurisdiction), such as, teaching assistant, teaching aide, learning support assistant, learning support officer, paraprofessional, paraeducator and special needs assistant (Giangreco \& Doyle, 2007). In the current paper, we refer to such individuals as teaching assistants. These individuals operate within an Australian primary education system that strives to be inclusive, such that students with additional learning needs are included in general education classrooms and schools receive funding for the employment of teaching assistants. It is acknowledged that, around the world, the above-mentioned personnel assist teachers; however not necessarily always with teaching (Giangreco \& Doyle, 2007). For example, the focus of a teaching assistant's role might be around behaviour management or classroom administrative responsibilities. 
Teaching assistants are not tertiary qualified teachers; however, they do require a Certificate III or Certificate IV in Education Support to gain employment in an Australian school. They will also frequently undertake additional professional learning once within the school system, for example, through professional development courses, such as the three day course offered through the G.R.I.N. program.

Teaching assistants may deliver complementary instructional support, designed to supplement rather than replace the instruction provided by teachers (Giangreco, 2013; Salend, 2016). This may occur through them working directly with specifically funded students with additional learning needs and/ or operating in a broader capacity across the classroom/ school, in part to free up teachers to more effectively meet the learning needs of specifically funded students. There is therefore a great deal of autonomy and flexibility in terms of how schools choose to incorporate teaching assistants to support instruction in Australian schools.

A recent systematic review by Sharma and Salend (2016) revealed that the pre-conditions for teaching assistants to be efficacious in their role included "effective communication and collaboration, role clarification, planning time with supportive teachers, targeted professional learning for them and the teacher with whom they work, and being observed by and receiving feedback from other professionals" (p. 124). Similarly, Devecchi and Rouse (2010), in their study exploring the features of effective collaboration between teachers and teaching assistants emphasised the importance of teachers and teaching assistants consistently sharing information, including knowledge, skills, ideas and resources; having clear but also flexible roles and responsibilities, and being both approachable and professionally respectful.

Although there is evidence that the roles and responsibilities of teaching assistants have become more instructionally focussed in recent years (Fisher \& Pleasants, 2012), these individuals are not always utilised as effectively as they might be to support learning in the classroom (Giangreco, 2013; Sharma \& Salend, 2016). However, there is some evidence that providing targeted professional support to leaders, teachers and teaching assistants, can result in teaching assistant roles being more focussed on supporting instruction, including in the context of the mathematics classroom (Warren, Cooper, \& Baturo, 2004).

Specifically, in one of the few studies that examined the role of teaching assistants in mathematics classrooms, Warren et al. (2004) report on a professional learning initiative implemented across twelve classrooms in three majority Indigenous-student schools. The initiative was designed to support teachers to implement project-based mathematics learning in the study schools. Although the intended focus was on providing professional support for teachers to develop their mathematical content knowledge and foster learning opportunities for students, as the year progressed, the scope was extended to directly support the teaching assistants and to address teacher relationships with the teaching assistants. It was identified that teaching assistants tended to be used for behaviour management, rather than instructional support, particularly Indigenous teaching assistants. However, as the initiative unfolded, this perception shifted and teaching assistant roles became more instructional in focus. The authors speculate that this shift was a consequence of the teaching assistants gaining more knowledge and confidence and/ or teachers realising that teaching assistants had been previously under-utilised.

Building on from Warren et al.'s (2004) findings, we would argue that involvement in the G.R.I.N. program constitutes a highly effective use of teaching assistants through both its provision of targeted professional support and the overall program structure. Giangreco (2013) synthesises the research literature to argue that the instructional work of teaching assistants needs to be consistent with several principles. First, teaching assistant instructional work should complement and not replace classroom teacher instruction. Second, the teacher should be responsible for developing evidenced-based instructional plans that the teaching assistant implements. Third, the teaching assistant should receive appropriate training and support around how to implement these instructional plans. We contend that teaching assistant involvement in the G.R.I.N. program is desgined to be consistent with these principles. First, the purpose of participating in G.R.I.N. is to frontload the learning prior to the group of students partaking in the mathematics lesson alongside the rest of the class. Second, the teacher is expected to share their mathematics planning with the teaching assistant, and support them to plan their G.R.I.N. session accordingly. Third, the expectation is that the teaching assistant undertakes the G.R.I.N. training alongside the mathematics teacher, so they both have an understanding of the program's design and intent. The extent to which the apparent alignment between the G.R.I.N. program's design and the good practice principles of utilising teaching assistants highlighted by Giangraco (2013) might manifest in practice is part of the focus of the current study. 


\section{The Current Study}

Previous research into the G.R.I.N. program focused on the perceptions of G.R.I.N. from the perspective of tutors and teachers to examine the successes and challenges of the program in terms of re-engaging previously disengaged students with their mathematics learning (Kalogeropoulos et al., 2020). The current study is part of a larger, design-based research project tasked with inquiring into the relationships between the appointed G.R.I.N. tutors and their partnered mathematics teachers, in an attempt to understand the different models used to plan and implement G.R.I.N. in a school setting. The broader goal of this project is to establish several viable models representative of good practice within the G.R.I.N. program.

In this paper, we report on phase one of this design-based research project. It involved a focussed study with a single school that had implemented G.R.I.N. with apparent success. Data were collected through in depth interviews with teachers and tutors (comprising three distinct teacher-tutor dyads) as well as the Numeracy Leader responsible for overseeing the program. All three tutors at the study school were employed as teaching assistants. Our research question is: How do teacher-assistant dyads operationalise classroom planning in a successful G.R.I.N. project school?

The objective of phase one is to synthesise (at least) one potential model of good practice within the G.R.I.N. program that can be presented as a prototype to schools considering implementing G.R.I.N. in the future. Phase two will examine how these future schools engage with this prototype model, including the extent to which it is adopted, adapted, or re-imagined to fit with a given school's local context.

\section{METHOD}

The research on which this paper reports is on data gathered from semi-structured interviews with mathematics teachers and their partnered tutors from one specific primary school in outer Metropolitan Melbourne (approx. 250 students; 14\% language background other than English). The school was selected for inclusion in our study based on two criteria:

- that the staff involved agreed to participate in follow-up interviews about the school's experience with the G.R.I.N. program;

- that the G.R.I.N. program had been successfully implemented at the school, as reported by school leadership, and evidenced by the school's interest in continuing with the program, and positive reports around student engagement and mathematics learning.

In total, six educators were interviewed: the Numeracy Leader, three classroom teachers and two G.R.I.N. tutors (the remaining tutor was unavailable for interview). The interviews were designed to probe mathematics teachers and tutors to describe how G.R.I.N. was implemented in their classroom context. In particular, the interviews focused on participants' descriptions of the working relationship between themselves and the other educator (or in the case of the Numeracy Leader, their observations of these relationships), as well as program logistics.

One of the primary purposes of interviewing both members of each dyad individually (when possible) was to triangulate the data, to ensure confidence in our findings. However, in terms of our approach to the data analysis, each dyad is described as a single case. Within each of these descriptions, comments from multiple interviews are integrated into a single, coherent narrative of the dyads approach to the G.R.I.N. program, with any contradictory or conflicting comments between different interviewees noted.

Our overall approach to the research and data analysis are consistent with principles of design-based research, given our concerns linking "processes of enactment to outcomes" (Design-Based Research Collective, 2003, p. 7). This involves examining how the nature of the teacher-tutor working relationships in this particular school context shaped how G.R.I.N. was implemented, and how it supported the success of the program. As stated previously, our objective is to attempt to synthesise one particular model for the G.R.I.N. program that emerged from this particular school's context, which is likely to have more general application. Effectively, we are attempting to generate "models of successful innovation", that can be shared with other communities of practice (Designed-Based Research Collective, 2003, p. 7).

\section{RESULTS}

Our discussion of the data begins by separately considering the Numeracy Leader's role in implementing the G.R.I.N. program at the school. This is followed by drawing on interviews with the teachers and tutors 
(and, where relevant, the Numeracy Leader) to describe the approach to the G.R.I.N. program adopted by the three dyad pairs. Throughout both these sections, illustrative quotes from participants are provided. The approach of these three dyad pairs are then compared and contrasted, and notable underlying similarities and differences highlighted. We conclude by synthesising these findings to offer a potential model for G.R.I.N. that other primary schools taking on the G.R.I.N. program, or other similar intervention programs, might consider adopting.

\section{The School's Overall Approach to G.R.I.N: Interview with Sam (Numeracy Leader)}

The Numeracy Leader Sam provided the overall picture of the G.R.I.N. program at the school. As noted previously, Sam described how, at their school, there were three tutors coupled with three respective classroom teachers who were responsible for mathematics instruction. The tutors appointed were teaching assistants that were currently working in the three chosen classrooms. Sam described that this was intentional as it was believed that the familiarity between the staff would assist and accelerate the implementation of the G.R.I.N. program, as the teacher and tutor were already accustomed to working together closely.

I think because all the tutors know the teachers, they probably had working relationships with them anyway, so that was probably a bonus to begin with and the way we set it up.

We can refer to this aspect of the school's model as embedding the tutor in the classroom.

Sam explained that initially meetings were organised with the entire G.R.I.N. team (including the school principal, the Numeracy Leader, the teachers and the tutors that would be involved), to discuss timetabling, the responsibilities of each person and the importance of planning and making any planning documents available to the tutors. During these meetings, it was suggested that it might be preferable to have the G.R.I.N. sessions on the same day as the corresponding mathematics lesson. Sam explained that teachers were told about the importance of suggesting suitable activities for the tutors to implement in the G.R.I.N. session. These early meetings thus helped to establish role clarity, and a shared understanding of the program.

We had a couple of meetings with tutors and teachers to talk about how the program would work and what the responsibilities of the tutors were and the responsibilities of the teachers, so the teachers knew they had to provide the tutors with the concepts that were being taught and maybe some suggested activities and things like that.

Other meetings addressed issues and challenges that were anticipated and whilst the leader provided advice on how these could be resolved, ultimately each teacher-tutor pair were left to work out a system that would work best for them in implementing G.R.I.N. This decision to devolve responsibility to individual dyads to troubleshoot challenges at the classroom level highlighted the emphasis on flexibility, and the value placed on allowing tutor-teacher dyads to operate with autonomy.

So I think we kind of trialled it first to see how it would work, and we had a couple of meetings as a team to talk about any issues that were going on, and I think each pair worked out a system that would work best for them.

An area that the Numeracy Leader identified as particularly important to an effective working relationship between the teacher and the tutor was clear and regular communication. This need for clear and regular communication was described by Sam as being important across a number of program domains, including when planning G.R.I.N. sessions, when providing feedback to each other regarding activities, and when considering students' understanding of mathematical concepts.

I think probably the main thing...is just having time to talk with each other, for the tutors to find out what does the teacher want them to teach and then to give feedback about how the students are going.

\section{Dyad 1: Bronwyn (Teacher) and Ricky (Tutor)}

The dyad of Bronwyn (teacher) and Ricky (tutor) operated in a composite class of Year 3/4 students ${ }^{1}$. Both Bronwyn and Ricky explained that their G.R.I.N. sessions were planned before school on the day that the session was delivered, over a "cup of coffee". Bronwyn and Ricky described adopting this daily-planning

${ }^{1}$ Note, in Australia, children are generally eight years old at the beginning of Year 3, nine years old at the beginning of Year 4 etc. 
approach to ensure that what was planned for G.R.I.N. was delivered. For example, they both spoke about preferring not to plan too far in advance, as there were many interruptions to the timetable.

So that's the bonus I feel of doing it that morning, that it's not set in concrete, she hasn't planned her three sessions for the week and that's just how it's going to stay, it's got fluidity to meet the needs of the students. Bronwyn

We think it works best that way because, if I was to do it the week before - if we had a time slot a week before, things change in the week and then you put the effort in and it's not happened. Ricky

Also, a daily-planning approach gave them an opportunity to review the previous mathematics lesson and only move on if they were comfortable that the students (both G.R.I.N. students and other students in the class) had shown adequate understandings and progress.

It's quite an honest conversation and if she thinks that what I'm targeting, asking her to target in the G.R.I.N. session is not where they're up to, she's quite confident in being able to say to me, "No, I don't think they've got that yet, or they know that, I think we need to look at something else". Bronwyn

I need to know what her expectation is and she needs to know what my limitations are, and we seem to work with that well. Ricky

Bronwyn and Ricky explained the importance of being flexible in their approach with the delivery of G.R.I.N., focusing on student progress rather than content that needed to be covered. Bronwyn noted that there were times when she needed to re-direct Ricky if she determined that the G.R.I.N. activity suggested by Ricky could have been replaced with a more effective task. Bronwyn explained that Ricky accepted constructive criticism positively and that this characteristic allowed them to deliver an effective G.R.I.N. program to students. This suggests that Bronwyn and Ricky had an open and professionally respectful relationship.

So, we have a two way conversation, it's not just me dictating the lesson to her. Bronwyn

Yeah, I helped with the testing, and my opinion was asked about whether I thought that these children would be a good fit. Ricky

The fact that Ricky was appointed as a teaching assistant in Bronwyn's class allowed Ricky to not only conduct the G.R.I.N. session but also be part of the subsequent mathematics lesson. This meant that Ricky could observe the G.R.I.N. students and offer additional support in session, whilst also enabling her to monitor misunderstandings, progress and achievement that could then be discussed with Bronwyn to inform future G.R.I.N. (and mathematics) planning during their informal post-lesson debrief. Ricky's superior knowledge of the G.R.I.N. students in general, and the G.R.I.N. students' experience of the mathematics classroom in particular, appear to be clear and distinct advantages of having the tutor embedded in the classroom.

Yeah, I think for them [the tutor] to see... because getting feedback to them about how their session went, has it informed the kids? Has it helped the kids? But also the next steps, what's going to happen next or having the confidence to have that pedagogical understanding because they've seen it in action in the lesson too, I think is helpful for them. Bronwyn

I think it's probably helpful because if the child's not sure of something, I can then say "Oh well, look, remember we touched about that just outside G.R.I.N.", or "Is it in our book? Can that help you?", and I can just give them an example of something that they might have done outside, and they'll go "Oh yeah. That's right. That's what we did". So, I think it is good to do that, although when I am back in the class, I'm not there for those children, I'm there for different children, but of course you're still watching to see what's going on. So, I think it is helpful for them to have me back in there where I can just give them a prompt if they need it. Ricky 


\section{Dyad 2 - Ramona (Teacher) and Jamie (Tutor)}

The dyad of Ramona (teacher) and Jamie (tutor), who worked in a composite Year 5/6 classroom, followed a somewhat different approach when implementing the G.R.I.N program. Rather than daily meetings on the morning before the G.R.I.N session and subsequent mathematics lesson (as per Bronwyn and Ricky), Ramona and Jamie met twice a week to plan and discuss G.R.I.N. "over lunch".

Jamie and I, we usually spend probably two lunchtimes a week doing this. It would be nice to have [additional] time to plan together, but we don't, so yeah, that's what we do. Ramona

During this time, they had a conversation, sharing ideas regarding possible G.R.I.N. activities and student goals. Jamie paid particular attention to the language that was to be used in the subsequent mathematics lesson, ensuring that the vocabulary used in the G.R.I.N. session mirrors exactly the vocabulary Ramona introduced in the classroom. Ramona explained that she valued Jamie's opinion highly, as Jamie had substantial experience working as a G.R.I.N. tutor in upper primary classrooms.

We'll sit down and nut it out together, but she's got a lot of good knowledge as well. Jamie's been in senior school for quite a few years before I've come up here, so she's got a lot of valuable input too and I think it's important that she is recognised for that. Ramona

Jamie concurred that her pre-existing knowledge of the children she worked with, as well as her experience in the upper primary classroom more generally, was advantageous for supporting the delivery of G.R.I.N.

I think some of it is that these students have known me as well, so it's since they were Prep [Foundation], really, but they've known me through school, so it's not been a hard relationship to then build on because we have had previous interactions with each other. Jamie

I've noticed over the years I've been in 5/6, people use different language with just the same algorithm or the same formula, they all have a different way of doing it. Jamie

Ramona ensured that Jamie had access to her planning, data and anecdotal assessments on Google Docs and in return, she had access to Jamie's notes from both the G.R.I.N. sessions and classroom observations. The pair described the relationship as a partnership, and it was clearly characterised by a similar level of openness and professional respect as Bronwyn and Ricky.

And we'll sit down and have a chat and she'll say, "This is what I think", and I'll say, "Well this is what I think. This is how we could get them there"... It's a partnership... I think relationship is key. Ramona

She's very open to giving her information of how she teaches, the way she teaches that whatever we're doing at the time in math and very happy to give me feedback on the students, I suppose on how to go about a task if I don't understand where the direction is going for that math lesson. Jamie

Again, the fact that this dyad also worked in the same physical space together allowed them to provide each other with feedback, and to plan future goals after the lesson had ended. Ramona and Jamie explained that they shared a vision of good teaching practice and were flexible as to how content was delivered. They were also understanding and accommodating to changes or interruptions to the program, especially when concepts needed to be revisited for improved student understanding. As a principle for resolving conflicts as they arose, the pair placed students at the centre and attempted to prioritise what was best for them.

Neither of us are very set in our ways, which is good, because we need to make sure that we can accommodate those changes, because, as you would know, it's nice to set up with a plan but very rarely does it go to plan. I think that's good for us. We're both flexible in that and happy to go: "well actually, today I noticed this, so we're going to change tomorrow and do it this way"... But I think we're pretty open with each other, we have that sort of professional respect for each other, where I value her opinion and she values mine, and we work to find that middle ground that's going to be the best for the kids. I 
think that comes down to that we share the belief that it's not about me, it's not about

her, it's about the kids. Ramona

Ramona and Jamie described that they would have liked more opportunities to have regular meetings with other educators (especially at the same year level), as this could have provided a forum for sharing ideas around the most effective means of supporting their students. Although regular co-planning time with other teacher-tutor dyads had not been made available, it was clear that leadership had taken active steps to increase the quality and coherence of the G.R.I.N. program's delivery. For example, Jamie noted that the Numeracy Leader Sam had facilitated Ramona to be released from the classroom to observe some of the G.R.I.N. program sessions conducted by Jamie. In addition, the school principal had observed a G.R.I.N. session, paying attention mostly to the level of student engagement.

[Sam's] been able to stand in and just watch Ramona's class so Ramona has sat and seen sometimes what we've done. Sometimes, the principal has come and sat down and watched the students interact with G.R.I.N. to see how the kids are being. Jamie

\section{Dyad 3 - Damien (Teacher) and Joan (Tutor)}

Our final dyad was comprised of Damien (teacher) and Joan (tutor), who worked together in a composite Year 3/4 classroom. Only Damien was available to be interviewed, so the data from this dyad is not triangulated to the same degree as the previous two dyads discussed. Damien described himself as fortunate enough to have worked with Joan for three years prior to G.R.I.N., in her teaching assistant role in his classrooms.

We know each other. We understand how each other works and we've had that process happening with other things in the classroom, before the G.R.I.N. program was in place, about what we want to do and how we want to do it and who we're working with and the focus and how we go about it.

This had provided the pair with opportunities to develop a close working relationship. The pair regularly discussed student understanding of mathematical ideas, assessment results and student misconceptions to inform their future planning.

In terms of academic understanding, we might have a chat about that. We'll get some testing results or some previous activities and see where the students have gone wrong, or taken it in the wrong direction, or whatever it might be.

Damien made a conscious effort to address important mathematics strategies with Joan to ensure that these were introduced in the G.R.I.N. sessions; for example, emphasising strategies founded in conceptual understanding rather than teaching the addition algorithm.

There are several addition strategies we expose them to, so it's just touching base and making sure she knows which one we are teaching.

Damien also described the advantage of having the tutor be someone employed as a regular teaching assistant in his classroom. He noted that this allowed Joan to connect the G.R.I.N. students' experiences in the G.R.I.N. sessions with their demonstrated understandings and progress in the classroom, and to convey this information to Damien in real time.

She will have them in the G.R.I.N. program and in the classroom she can keep an eye on them and see how they're going and if what she has done with them has transferred.

This also informed future G.R.I.N. session planning. Damien was responsive to Joan's request that G.R.I.N. be timetabled as a session prior to the mathematics lesson by making appropriate changes to the timetable.

I rearranged my timetable so that G.R.I.N. would work better so that there would be a G.R.I.N. session going into a maths lesson. 


\section{DISCUSSION}

As discussed in the introduction, a number of conditions need to be met for teaching assistants to be highly effective in their roles. Such conditions include: open communication, information sharing and collaboration, having clear yet flexible roles, being allowed sufficient planning time with teachers, having access to professional learning and being included in professional networks with their teacher colleagues, and being given professional respect (Devecchi \& Rouse, 2010; Sharma \& Salend, 2016). There is evidence that these conditions were present for each of the three dyads described in our current study.

As reflected by Sam in his interview, in part, this reflects the structure of the G.R.I.N. program itself. Through the three professional learning days, the G.R.I.N. program has the potential to promote a professional working relationship between the teacher and appointed tutor at the outset. To begin with, teachers, tutors and a member of the school leadership team (e.g., principal or Numeracy Leader) must all attend the first professional learning day of the G.R.I.N. program (Day 1). This day focuses on explaining the G.R.I.N. model but also provides an opportunity for school teams to discuss the implementation of the program at their school. On Day 2 and Day 3, teachers and tutors are encouraged to work together in identifying and designing tasks for the G.R.I.N. program. This involves extensive communication and information sharing between the teacher and the G.R.I.N. tutor regarding the philosophy of good teaching practices, content knowledge and ideas for effective task design.

In the school environment, teachers and G.R.I.N. tutors continued to communicate, collaborate and clarify their roles through ongoing planning. In one dyad, we were presented with a more informal style of planning, where Bronwyn and Ricky met in the morning before school to discuss the G.R.I.N. program before the day commenced. The focus in these meetings was on student progress and achievement to determine if a mathematical concept needed to be revisited or whether students were ready to explore a different topic. This informal approach to planning demonstrated a flexibility in their working style. The dyad consistently shared resources and professional knowledge; in particular Bronwyn provided advice to Ricky in selecting the most appropriate task for the G.R.I.N. session and this was received positively. The pair communicated effectively, supporting each other during mathematics lessons and informally discussing what they noticed in terms of student understandings and misconceptions.

The dyad of Ramona and Jamie presented us with several similarities but a few subtle differences in terms of how they approached their planning of the G.R.I.N. program. This pair also created their own collaborative planning time, and met twice a week during lunchtime to discuss the G.R.I.N. program having previously studied the shared teacher planner. Similar to the first dyad, Ramona and Jamie also used this time to discuss student progress, and the content of the G.R.I.N. sessions. Although this pair did not touch base just prior to daily mathematics lessons, or G.R.I.N. sessions, Ramona and Jamie dedicated some time to discussing what they noticed in class time after the lesson had ended through an informal 'debrief'. This structure again helped to support flexibility and a collaborative approach. In this dyad, Jamie, as the tutor, was instrumental in the implementation of G.R.I.N. due to her extensive experience with the program. Jamie also mentioned her desire to network with other teachers and G.R.I.N. tutors to share experiences and resources, demonstrating an interest in receiving feedback from other professionals.

In the third dyad, Damien described an ongoing professional relationship with the G.R.I.N. tutor. Working harmoniously together for three years had provided them with an effective and established partnership. One can assume that they had developed their ability to communicate clearly and to collaborate productively, supporting their capacity to ensure role clarify during the G.R.I.N. program, as well as co-plan effectively. This was indicated through Damien noting that the G.R.I.N. sessions were planned together and these planning sessions were based on combined classroom observations of student progress and understandings. Damien provided feedback to Joan to ensure that appropriate strategies were modelled for solving mathematical problems in G.R.I.N (e.g., an emphasis on conceptual strategies, rather than the traditional algorithms). In addition to this, the tutor influenced Damien to make changes to the timetable for the G.R.I.N. session to be directly before the mathematics lesson. This was an indication that this pair respected each other's professional opinions and worked flexibly to deliver an effective intervention program.

\section{CONCLUSIONS AND SYNTHESIS}

The data seems to suggest that the successful implementation of the G.R.I.N. program depends on specific aspects of the professional relationships between the teachers and the tutors in the programs planning and 


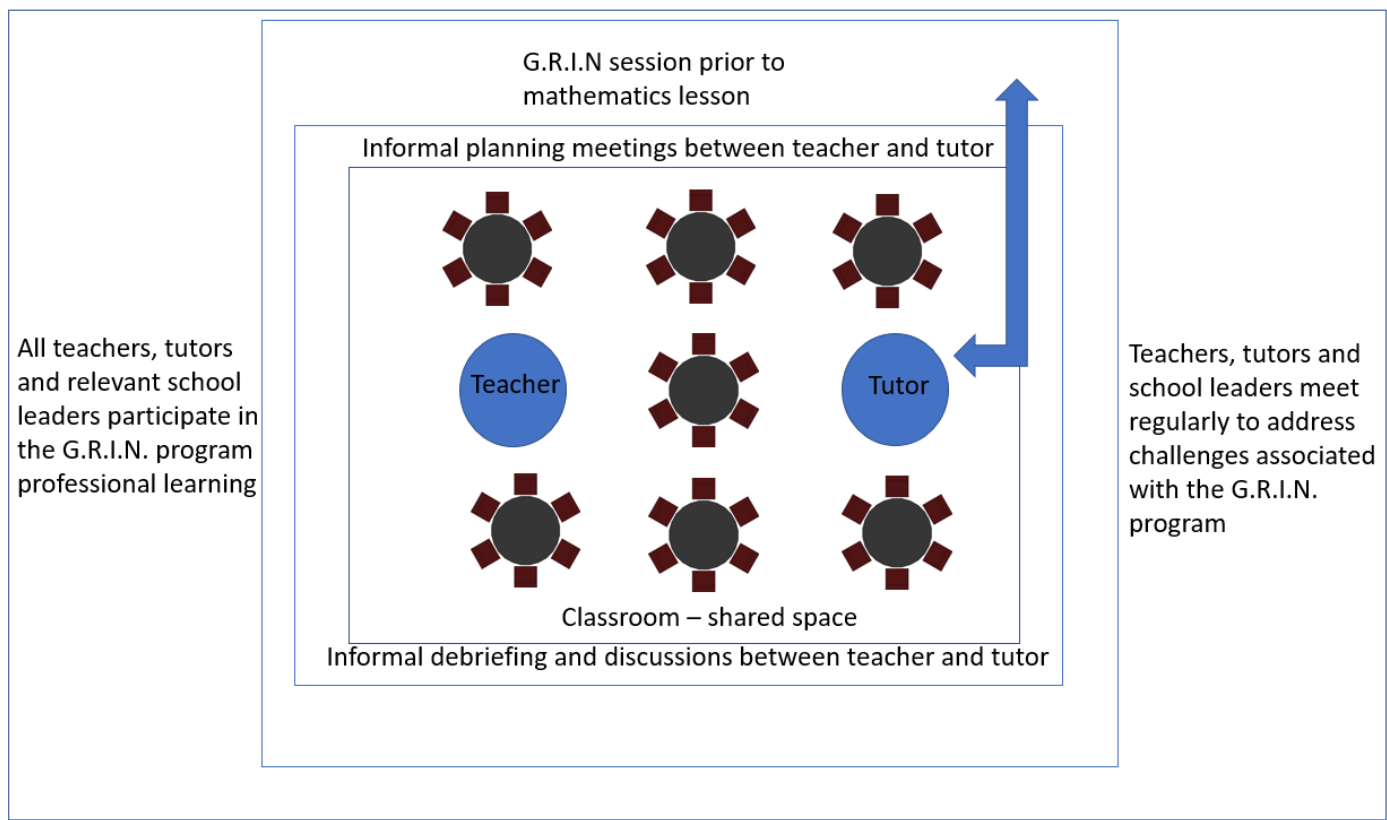

Figure 1. An embedded tutor model for the G.R.I.N. program

delivery; however, there were several notable commonalities across the three dyads that are worth highlighting. Perhaps primarily, it seems to be beneficial for current teaching assistants to operate as G.R.I.N. tutors in their home classrooms; what we might refer to as the embedded tutor model. Regularly sharing the classroom space facilitates effective communication and collaboration between the tutors and teachers. This allows tutors (and teachers) to observe the G.R.I.N. students in their subsequent mathematics lesson, noticing student understandings, misconceptions and their ability to "keep up" with the rest of the class. These observations in turn serve as conversation starters to inform subsequent G.R.I.N. planning. In addition, all three dyads noted that their G.R.I.N. sessions were either immediately before the corresponding mathematics lesson or on the same day; and Sam confirmed that this was the approach to G.R.I.N. that the school endorsed. This appeared to ensure that the G.R.I.N. session could be flexibly tailored to fit with the subsequent mathematics lesson. To support this flexibility, all three dyads generally met either informally before the G.R.I.N. session at the beginning of the day (e.g., Bronwyn and Ricky) and/or after the previous mathematics lesson to both debrief and touch-base about the following G.R.I.N. session (e.g., Ramona and Jamie). It is worth noting that such informal approaches to planning were also necessary, as G.R.I.N. dyads were not provided with formal allocated planning time, but had to flexibly construct their own. A model describing these common practices across the three dyads in our study school is outlined in Figure 1.

One exciting aspect of the embedded tutor model outlined in Figure 1 is that it appears to constitute a highly effective use of teaching assistants, consistent with many of the principles outlined in the inclusive education literature (Devecchi \& Rouse, 2010; Giangreco, 2013; Sharma \& Salend, 2016). Consequently, it may be that the model outlined here could inform both the inclusive education literature, and the mathematics intervention literature more generally, through providing an example of an approach that:

- involves specialised intervention to support students experiencing learning difficulties (G.R.I.N.), whilst still allowing these students to participate in whole class instruction;

- provides professional support and professional learning experiences to teaching assistants to develop their skills and support their capacity to be effective in their roles;

- empowers teaching assistants to make decisions in a context which they experience role clarity, and where the key pedagogical decisions are still being driven by the expertise of the classroom teacher and other relevant professionals (e.g., Numeracy Leader);

- frames the classroom teacher and the teaching assistant relationship as a meaningful partnership, characterised by professional respect and a common mission.

Given the emphasis on partnership and genuine collaboration between the classroom teacher and teaching assistant, future research may wish to focus on how the quality of these relationships are impacted on by the 
degree to which teacher and tutor values regarding the learning of mathematics are aligned. Values alignment between teachers and their students appears to have implications for the efficacy of mathematics instruction, and student engagement in mathematics in particular (Kalogeropoulos, 2016). For a teacher or a tutor, being able to facilitate values alignment with their co-workers (and students) promises to strengthen these relationships, and is likely to be a key component to nourishing teaching and learning practices (Seah \& Andersson, 2015).

The current study constituted the first phase of a broader designed-based research project. It was concerned with synthesising (at least) one model of good practice to present to future schools considering implementing G.R.I.N. The second phase will involve presenting the current embedded tutor model to these future schools as a prototype of teacher-tutor collaboration, which can be subsequently modified (and, in some instances, even transformed) based on the unique characteristics, opportunities and constraints of the relevant school.

\section{Disclosure statement}

No potential conflict of interest was reported by the authors.

\section{Notes on contributors}

Penelope Kalogeropoulos - Monash University, Australia.

James Russo - Monash University, Australia.

Toby Russo - Victorian Department of Education, Australia.

Peter Sullivan - Monash University, Australia.

\section{REFERENCES}

Design-Based Research Collective. (2003). Design-based research: An emerging paradigm for educational inquiry. Educational Researcher, 32(1), 5-8. https://doi.org/10.3102/0013189x032001005

Devecchi, C., \& Rouse, M. (2010). An exploration of the features of effective collaboration between teachers and teaching assistants in secondary schools. Support for Learning, 25(2), 91-99. https://doi.org/10.1111/j.1467-9604.2010.01445.x

Fisher, M., \& Pleasants, S.L. (2012). Roles, responsibilities, and concerns of paraeducators: Findings from a statewide survey. Remedial and Special Education, 33, 287-297. https://doi.org/10.1177/0741932510397762

Giangreco, M. F., \& Doyle, M. B. (2007) Teacher assistants in inclusive schools. In L. Florian (Ed.), The sage handbook of special education (pp. 429-439). London: SAGE.

Giangreco, M. F., (2013). Teacher assistant supports in inclusive schools: Research, practices and alternatives. Australasian Journal of Special Education, 37(2), 93-106. https://doi.org/10.1017/jse.2013.1

Kalogeropoulos, P. (2016). The role of values alignment in engagement and (dis)engagement in mathematics learning. (Unpublished doctoral dissertation). Monash University, Melbourne.

Kalogeropoulos, P., Russo, J. A., Sullivan, P., Klooger, M., \& Gunningham, S. (2020). Re-enfranchising Mathematically-alienated Students: Teacher and Tutor Perceptions of the Getting Ready in Numeracy (GRIN) Program. International Electronic Journal of Mathematics Education, 15(1), em0545. https://doi.org/10.29333/iejme/5881

Salend, S. J. (2016). Creating inclusive classrooms: Effective, differentiated and reflective practices (8th ed.). Columbus, OH: Pearson.

Seah, W. T., \& Andersson, A. (2015) Valuing diversity in mathematics pedagogy through the volitional nature and alignment of values. In Bishop, A., Tan, H. \& Barkatsas, T. (Eds.) Diversity in mathematics education: Towards inclusive practices (pp. 167-183). Dordrecht, The Netherlands: Springer. https://doi.org/10.1007/978-3-319-05978-5_10

Sharma, U., \& Salend, S. J. (2016). Teaching assistants in inclusive classrooms: A systematic analysis of the international research. Australian Journal of Teacher Education, 41(8), 118-134. https://doi.org/10.14221/ajte.2016v41n8.7 
Sullivan, P., \& Gunningham, S. (2011). A strategy for supporting students who have fallen behind in the learning of mathematics. In J. Clarke, B. Kissane, J. Mousley, T. Spencer, \& S. Thornton (Eds.), Mathematics: Tradition and [New] Practices. Proceedings of the 34th Annual Conference of the Mathematics Education Research Group of Australasia and the Australian Association of Mathematics Teachers (pp. 719-727). Adelaide: AAMT and MERGA.

Warren, E., Cooper, T. J., \& Baturo, A. R. (2004). Indigenous students and mathematics: Teachers' perceptions of the role of teacher aides. The Australian Journal of Indigenous Education, 33, 37-46. https://doi.org/10.1017/S1326011100600856

http://www.iejme.com 